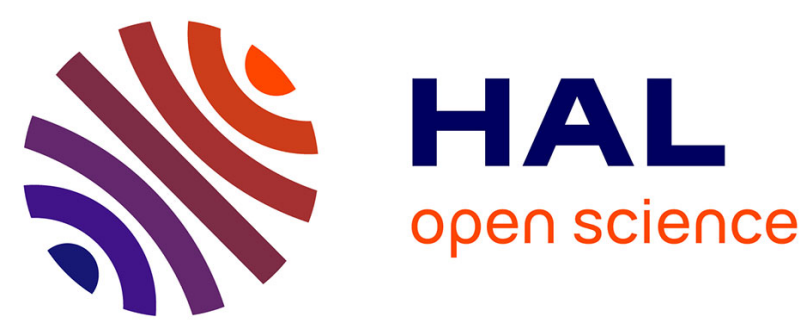

\title{
Incorporating food-web parameter uncertainty into Ecopath-derived ecological network indicators
}

Vanessa Guesnet, Géraldine Lassalle, Aurélie Chaalali, Kelly Kearney, Blanche Saint-Béat, Battle Karimi, Boutheina Grami, Samuele Tecchio, Nathalie Niquil, Jérémy Lobry

\section{To cite this version:}

Vanessa Guesnet, Géraldine Lassalle, Aurélie Chaalali, Kelly Kearney, Blanche Saint-Béat, et al.. Incorporating food-web parameter uncertainty into Ecopath-derived ecological network indicators. Ecological Modelling, 2015, 313, pp.29-40. 10.1016/j.ecolmodel.2015.05.036 . hal-01186765

\section{HAL Id: hal-01186765 https://hal.science/hal-01186765}

Submitted on 16 May 2020

HAL is a multi-disciplinary open access archive for the deposit and dissemination of scientific research documents, whether they are published or not. The documents may come from teaching and research institutions in France or abroad, or from public or private research centers.
L'archive ouverte pluridisciplinaire HAL, est destinée au dépôt et à la diffusion de documents scientifiques de niveau recherche, publiés ou non, émanant des établissements d'enseignement et de recherche français ou étrangers, des laboratoires publics ou privés. 
1 Highlights:

2 - The ENAtool routine relies on an ensemble parameterization technique

3 - It incorporates the uncertainty in EwE inputs into the calculation of ENA indices

4 - The ENAtool routine was applied on the Bay of Biscay continental shelf Ecopath model

5 - The previously ENA-derived structural and functional properties were strengthened

6 - Ecosystem comparative studies will now integrate statistical analyses on ENA indices 


\title{
Incorporating food-web parameter uncertainty into Ecopath-derived ecological
}

\author{
network indicators
}

${ }^{a}$ IRSTEA, UR EABX, Aquatic Ecosystems and Global Changes, 50 avenue de Verdun, 33612

Cestas cedex, France; vanessa.guesnet@yahoo.fr; geraldine.lassalle@irstea.fr;

jeremy.lobry@irstea.fr

${ }^{\mathrm{b}}$ CNRS, UMR 7208 BOREA, Université de Caen Basse-Normandie, Esplanade de la Paix, CS

14032, 14032 Caen cedex 5; France; aurelie.chaalali@gmail.com; samuele.tecchio@unicaen.fr;

nathalie.niquil@unicaen.fr

${ }^{\mathrm{c}}$ Cooperative Institute for Marine and Atmospheric Studies, University of Miami Rosenstiel

School of Marine and Atmospheric Science, NOAA Atlantic Oceanographic and Meteorological Laboratory, 4301 Rickenbacker Causeway, Miami, FL 33149, United States;

kkearney@rsmas.miami.edu

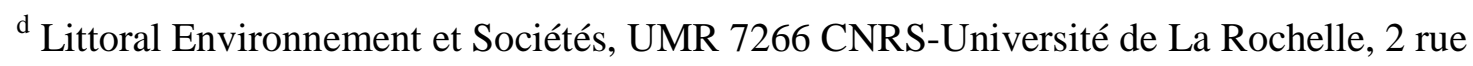

Olympe de Gouges, 17042 La Rochelle cedex, France; blanche.saintbeat@gmail.com

${ }^{\text {e } U M R ~} 6249$ Laboratoire Chrono-Environnement, Pôle Universitaire du Pays de Montbéliard, 4 place Tharradin, BP 71427, 25211 Montbeliard cedex, France; karimi.battle@ gmail.com

\footnotetext{
${ }^{1}$ Corresponding author. Tel.: +33557890802.

E-mail addresses: geraldine.lassalle@ irstea.fr; geraldinelassalle2@hotmail.com (G. Lassalle).

${ }^{2}$ Present address: IFREMER, Unité Écologie et Modèles pour l'Halieutique, Route de l'Ile d'Yeu, BP 21105, 44311 Nantes Cedex 03, France.
} 
๑. This manuscript version is made available under the CC-BY-NC-ND 4.0 license http://creativecommons.org/licenses/by-nc-nd/4.0/

28 f Laboratoire de Cytologie Végétale et Phytoplanctonologie, Département des Sciences de la Vie,

29 Faculté des Sciences de Bizerte, Université de Carthage, Zarzouna, Bizerte, Tunisia;

30 grami.boutheina@gmail.com 


\section{Abstract}

Ecological network analysis (ENA) provides numerous ecosystem level indices offering a valuable approach to compare and categorize the ecological structure and function of ecosystems. The inclusion of ENA methods in Ecopath with Ecosim (EwE) has insured their continued contribution to ecosystem-based management. In EwE, ENA-derived ecological conclusions are currently based on single values of ENA indices calculated from a unique input flow matrix. Here, we document an easy-to-use routine that allows EwE users to incorporate uncertainty in EwE input data into the calculation of ENA indices. This routine, named ENAtool, is a suite of Matlab functions that performs three main steps: (1) import of an existing Ecopath model and its associated parameter uncertainty values in the form of uncertainty intervals into Matlab; (2) generation of an ensemble of Ecopath models with the same structure as the original, and with parameter values varying based on the prescribed uncertainty limits; and (3) calculation of a set of 13 ENA indices for each ensemble member (one set of flow values) and of summary statistics across the whole ensemble. This novel routine offers the opportunity to calculate ENA indices ranges and confidence intervals, and thus to perform quantitative data analyses. An application of ENAtool on a pre-existing Ecopath model of the Bay of Biscay continental shelf is presented, with a focus on the robustness of previously-published ENA-based ecological traits of this ecosystem when the newly-introduced uncertainty values are added. We also describe the sensitivity of the ENAtool results to both the number of ensemble members used and to the uncertainty interval set around each input parameter. Ecological conclusions derived from EwE, particularly those regarding the comparison of structural and functional elements for a range of ecosystem types or the assessment of ecosystem properties along gradients of environmental conditions or anthropogenic disturbances, will gain in statistical interpretability. 
(c) This manuscript version is made available under the CC-BY-NC-ND 4.0 license http://creativecommons.org/licenses/by-nc-nd/4.0/

55 Key words: Ecopath with Ecosim; ecosystem models; network analysis; parameter uncertainty;

56 comparative studies

57 
1. Introduction

Marine ecosystems are affected by climate change (Beaugrand, 2004; Hoegh-Guldberg and Bruno, 2010) and by other natural or human-caused disturbances (Pauly et al., 1998; Borja et al., 2010). Ecosystem models are useful to get a better understanding of the structure and function of a system and for predicting how it may change over time when facing single or multiple pressures (Plagànyi, 2007). Ecopath with Ecosim (EwE) is a widely-used modelling approach to represent marine food webs (Polovina, 1984; Christensen and Walters, 2004; Christensen et al., 2008). Since its development in the early 1980s, about 400 EwE models representing a wide variety of ecosystems worldwide have been published (Colléter et al., 2013a; Colléter et al., 2013b). Coupling EwE models to Ecological Network Analysis (ENA; Ulanowicz, 1986) was proposed as a relevant method to estimate energy flows and to characterize emergent properties of food webs, i.e. characteristics not directly observable that can only be detected by analysis of within-system interactions (Christensen and Pauly, 1992). ENA is a suite of tools that include input-output analysis, trophic structure analysis, pathway analysis, biogeochemical cycle analysis, and information analysis (Dame and Christian, 2006; Borrett and Lau, 2014). The main challenge for ENA is to capture the properties of entire food web in terms of a limited number of indices. In the scope of the European Marine Strategic Framework Directive (MSFD; http://ec.europa.eu; Directive 2008/56/EC), the EU Member States have to report on the environmental status of the seas under their jurisdiction and to work on achieving "Good Environmental Status" (GES) using food-web indicators as one possible metric. In this direction, nine food-web indicators are currently under evaluation as potential indicators of GES; the Ecological Network Analysis indices are among these candidate indicators (Rombouts et al., 2013; Niquil et al., 2014). 
The EwE network analysis plugin has been employed in many instances, notably to study the stability of ecosystems and their response to perturbations (Patricio et al., 2006; Lobry et al., 2008; Baeta et al., 2011; Selleslagh et al., 2012) or, more recently, to assess the dynamical foodweb reorganization and redirection of energy flow pathways under environmental changes (Tomczak et al., 2013). Nonetheless, these holistic conclusions relied on single values of ENA indices which were derived from a single input data matrix with no specified uncertainty. Moreover, the ecological interpretation of these single values mostly relies on non-statistical comparisons with values obtained for ecosystems of the same type. Given that data uncertainties may translate to uncertainties in model outputs (e.g. Niiranen et al., 2012), it is generally agreed that important scientific questions should be scrutinized with as many models as possible (Fulton, 2010; Gårdmark et al., 2012). One method of incorporating uncertainty into Ecopath model analysis is to use an ensemble parameterization technique, building several Ecopath models each representing a potential manifestation of a food web and falling within the uncertainty ranges of the observed data (Aydin et al., 2007; Kearney, 2012). This approach results in distributions of parameters rather than specific values, while still meeting basic thermodynamic requirements. Kearney et al. (2012) provided a suite of Matlab functions to construct such a distribution of parameters based on an Ecopath model and its data pedigree, i.e. a quantification of the parameter certainty tied to the parameter's origin. In this study, we extend the Kearney et al. (2012) code for generating this type of ensemble to feed into calculations of ENA indices. This work will allow parameter uncertainty to be incorporated into modelderived ENA indices, and will also improve interpretation of these indices by allowing statistical analyses. When overhauling the EwE source code between the release of EwE versions 5 and 6, the EwE developers chose not to continue support of the Ecoranger module, which had allowed users to explore parameter uncertainty ranges in a Bayesian 
context (Christensen et al., 2005). The code presented in this paper now offers an

106

107

108

109

110

111

\section{alternative method for analyzing this uncertainty.}

The aim of this software development is to provide an easy-to-use routine to EwE users to generate a set of values for key ENA indices by explicitly taking into account uncertainty in model input data. To this end, two characteristics are identified as important: (i) a routine that can be called by a single line of Matlab code and can be run on all commonly-used operating systems (recent Windows, Unix-based, and Mac platforms), independent of the EwE software versions used for the pre-existing ecosystem model construction, and (ii) a routine based on formulas of ENA indices currently in use in the last version of the EwE software. The present work is also the opportunity to harmonize ENA indices calculations derived from two main approaches for constructing ecological flow networks, i.e. EwE and linear inverse modelling (LIM; Vézina and Platt, 1988). Different formulas for the same index exist in the scientific literature and correspond to different interpretations of the same idea. We demonstrate the use of this tool by applying it to a pre-existing Ecopath model of the Bay of Biscay continental shelf (Lassalle et al., 2011) for which data quality is already categorized using Pedigree scores (Lassalle et al., 2014). ENA indices distributions derived from the ENAtool routine are compared with previous point estimate values obtained with this Ecopath model to test for robustness of ENA-derived ecological conclusions. Finally, we test sensitivity of ENA indices distributions to the number of balanced ensemble members underlying their calculation and to the level of uncertainty applied to specific Ecopath model parameters.

\section{Materials and Methods}

2.1 The Ecopath concept and equations 
The Ecopath with Ecosim (EwE) modelling software enables the building and analysis of food-web models (Polovina, 1984; Christensen and Walters, 2004; Christensen et al., 2008). The full software package includes several modules (e.g. Ecopath, Ecosim, Ecospace) to explore food webs across both space and time. However, for this study, we will focus only on the Ecopath component, which calculates a static mass-balanced snapshot of the biomass and energy fluxes between functional groups in a food web. In this context, a functional group refers to a species or group of species that occupy a particular niche in the food web, and can range in resolution from a broad grouping (e.g. pelagic fish) to specific life stage of a species (e.g. juvenile herring). The Ecopath model calculation is based on two "master" equations. The first equation decomposes the production term of each functional group:

Production $=$ fishery catch + predation mortality + net migration + biomass accumulation + other mortality

"Other mortality" includes natural mortality factors such as mortality due to senescence, diseases, etc.

The second equation describes the energy balance within each functional group:

Consumption $=$ production + respiration + unassimilated food

More formally, the two equations can be written as follows for functional group $i$ and its predator $j$ :

$B_{i} \times(P / B)_{i}=Y_{i}+\Sigma_{j}\left(B_{j} \times(Q / B)_{j} \times D C_{i j}\right)+E x_{i}+B a c c_{i}+B_{i}\left(1-E E_{i}\right) \times(P / B)_{i}(1)$

and

$B_{i} \times(Q / B)_{i}=B_{i} \times(P / B)_{i}+R_{i}+U_{i}(2)$

where the main input parameters are biomass density $\left(B\right.$, here in $\left.\mathrm{kg} \mathrm{C} \cdot \mathrm{km}^{-2}\right)$, production rate $\left(P / B\right.$, year $\left.{ }^{-1}\right)$, consumption rate $\left(Q / B\right.$, year $\left.{ }^{-1}\right)$, proportion of $i$ in the $\operatorname{diet}$ of $j\left(D C_{i j} ; D C=\operatorname{diet}\right.$ 
151

152

153

154

155

156

157

composition), net migration rate $\left(E x\right.$, year $\left.^{-1}\right)$, biomass accumulation $\left(B a c c\right.$, year $\left.^{-1}\right)$, total catch $(Y$; $\mathrm{kg} \mathrm{C} \cdot \mathrm{km}^{-2}$ year $\left.^{-1}\right)$, respiration $\left(R ; \mathrm{kg} \mathrm{C} \cdot \mathrm{km}^{-2} \cdot\right.$ year $\left.^{-1}\right)$, amount of consumed food that is unassimilated $\left(U ; \mathrm{kg} \mathrm{C} \cdot \mathrm{km}^{-2} \cdot \mathrm{year}^{-1}\right)$ and ecotrophic efficiency $(E E$; amount of species production used within the system).

2.2 The generalized intra-model ensemble routine: ENAtool

In keeping with our goal to provide a single user-friendly tool for ENA index ensemble generation, we have packaged together a master Matlab script (ENAtool.m) and two data input templates, all of which are available via the Supplementary Materials. The ENAtool.m script grew out of, and now incorporates several sub-functions from, the Matlab implementation of Ecopath (Kearney, 2015; DOI:10.5281/zenodo.17837), with additional routines added to calculate ENA indices from the resulting model ensemble. The key calculations performed by this tool are as follows. All the Matlab functions called during the ENAtool routine operate only on Ecopath data.

\subsubsection{Import of a EwE model into Matlab}

ENAtool first imports data from EwE6 databases into Matlab, storing them in a variable format we will refer to as EwE input structures (Fig. 1). The original data import function, mdb2ewein, relies on the 'mdbtools' (http://mdbtools.sourceforge.net/) set of utilities to read data from the MS Access file format used by EwE. As an alternative for those unwilling or unable to compile C source code, we have provided a companion import function, excel2ewein, which relies on an Excel template to provide the necessary input data (Fig. 1). This function is based on a template (see Template A provided in Supplementary Material 2) that must be filled with key input parameters and other related information by first opening the pre-existing EwE model with a 
database program such as Microsoft Access or OpenOffice Base. The template was provided as an Excel file and can be completed using any spreadsheet program (e.g. Microsoft Excel,

OpenOffice Calc etc.) but must be in the end saved as an Excel file (.xlsx). Both functions

import all necessary Ecopath data, including basic inputs, diet compositions, fleet catches and discards, and multi-stanza group parameters, to the EwE input structure.

\subsubsection{Generation of a set of balanced ensemble members}

This second step can be decomposed into two phases: first, the definition of uncertainty around input parameters and then the construction of an ensemble of balanced Ecopath models (Fig. 1). A probability distribution for all or certain input parameters (i.e. field biomasses $(B)$, production over biomass ratios $(P / B)$, consumption over biomass ratios $(Q / B)$, ecotrophic efficiencies $(E E)$, and diet compositions $(D C)$ ) in the EwE input structure has to be defined. To do so, a level of uncertainty around each single value entered in the EwE input structure needs to be fixed.

Uncertainty values were assigned as a percentage of the point estimate of each parameter.

Minimum and maximum values of the parameter distribution can then be calculated as follows:

Limits $=$ single value of the parameter $+/-($ percentage $*$ single value of the parameter $)(3)$

In the present work, the createpedigree function was developed to ease this step, particularly in the case of pre-existing EwE models for which Pedigree scores were already estimated (Fig. 1; Table 1). The Pedigree index (Funtowicz and Ravetz, 1990; Pauly et al., 2000) was designed to evaluate whether an EwE model was based on extensive field sampling performed within the boundaries of the system during specific dates. The Pedigree component in the EwE software allows marking/categorizing the data origin of each single input using pre-defined tables; the key criterion being that inputs from local data have the best confidence and the highest level in the scale (Christensen et al., 2005). In the pre-defined tables, each Pedigree score is associated with a 
default level of uncertainty expressed as $\pm \%$. For example, a Pedigree score of 1 (e.g. for a local biomass value) indicates a $10 \%$ uncertainty value. The createpedigree function builds a table of uncertainties based on an Excel file which contains for each parameter and each functional group the level of uncertainty to be applied to the single value (see Template B in Supplementary Material 3). Again, this Excel file can be opened with any spreadsheet program but must be finally saved as an Excel file. This Excel file can be also an export of the Pedigree table from the EwE software. If the user has no estimate of the uncertainty surrounding the input parameters in the pre-existing EwE model, a level of uncertainty can be set and a matrix of the same dimension as the uncertainty table will be automatically generated. With no specification from the user, the default values will be $20 \%$ around single values (Richardson et al., 2006).

As inputs, the createensemble function requires the uncertainty table built using the createpedigree function and the model imported into Matlab using mdb2ewein or excel2ewein (Fig. 1). The createensemble function generates a defined number of ensemble members that all fall within the prescribed uncertainty ranges. Parameter values can be sampled from a uniform distribution within limits fixed by the uncertainty table or a lognormal distribution with the mean and standard deviation set according to the uncertainty table. Both Latin hypercube and MonteCarlo sampling methods can be used for random sampling in this interval. In the present application case, parameter values were randomly sampled using a Monte Carlo method from a uniform distribution with bounds directly related to the level of uncertainty.

The ecopathlite function called by the createensemble function is the one that reproduces the main calculations performed by the Ecopath module of the EwE software (Fig. 1). This function is a 'stripped-down' version of the Ecopath algorithms allowing an estimation of missing parameters by solving the system of $n$ equations with $n$ unknowns (see equations (1) and (2)). Users can also choose whether they want ensemble members that respect the biomass 
conservation hypothesis, i.e. here, that met the ecotrophic efficiency balance requirements (EE <1). Combining createensemble and ecopathlite functions allows the user to compute a specific number (referred to henceforth as nset) of balanced ensemble members before calculating any ENA indices. For multi-stanza configurations, adjustments of parameters are made when calling subecopathens.m to calculate Ecopath values and check for balance. So the resulting ENA index values stemming from this code will incorporate the same multi-stanza relationships as in EwE.

\subsubsection{Calculation of an ensemble of values for ENA indices}

Finally, the indices function was developed in this present work to calculate a set of 13 ENA indices (Fig. 1; Table 2) for each ensemble member generated by the createensemble function. The mathematical formulas for these indices required a harmonization between the EwE and LIM ecosystem modelling communities. We compared the formulas in use in EwE with those currently in use by modelers working with linear inverse models (LIMs) in Matlab (Leguerrier et al., 2007; Johnson et al., 2009; Niquil et al., 2011; Saint-Béat et al., 2013) (Table 2). Most formulas were shared in common between both communities and were as such already available in Matlab. Ecological interpretations of ENA indices are summarized in Table 2. Full details regarding their links with ecosystem ecology theories can be found, for instance, in Ulanowicz

241 (2004), Kones et al. (2009), and Saint-Béat et al. (2015).

245 A full description of the Bay of Biscay Ecopath parameterization can be found in Lassalle et al. 246 (2011). The model considered for this zone was restricted to the central part of the shelf between 
the $30-\mathrm{m}$ and $150-\mathrm{m}$ isobaths with a surface area of $102,585 \mathrm{~km}^{2}$ (Fig. 2). The model represented a typical year between 1994 and 2005, i.e. before the collapse of the European anchovy (Engraulis encrasicolus) and the subsequent five-year closure of the fishery for this species. Thirty-two functional groups were retained, including two seabirds, five marine mammals, nine fish, eight invertebrates, three zooplankton, two primary producers, one bacteria, discards from commercial fisheries, and pelagic detritus. Cephalopods were included in the form of two classes relating to their main oceanic domain (pelagic/benthic). The five main pelagic forage fish were given their own functional groups and demersal fish were divided into four multi-species functional groups on the basis of their diet regime. Marine mammals were included in the form of five mono-specific functional groups representing the small-toothed cetaceans most 257 frequently encountered in the area.

2.3.2 Summary of previous ENA-derived results

260 Some insights regarding the Bay of Biscay structure and function have been derived from ENA indices calculated with the EwE model of Lassalle et al. (2011) (see Table 2 for single estimates). In this previous work, single point estimates were interpreted by comparison to those obtained for ecosystems of the same type or for other Ecopath models of the same ecosystem. The high Finn's Cycling Index (FCI) value, which measures the relative importance of cycling to the total flow (Finn, 1980), highlighted the strategic position of detritus as a perennial reservoir of energy in the Bay of Biscay. The System Omnivory Index (SOI) was regarded as an index reflecting the complexity of the inner linkages within the ecosystem (Christensen and Pauly, 1992). It is correlated with system maturity, since the internal network organization is expected to increase as the system matures (Odum, 1969). The relatively moderate value for this output suggested a "web-like" food chain with an intermediate level of internal flow complexity. The Bay of Biscay 
also appeared as relatively immature, as indicated by the Ascendency (A), and has a high resistance to external perturbations according to System Overhead (O). Ascendency (A) merges

273 the quantification of the system activity and the degree of specialization of flows in the network

274 (Ulanowicz, 1986; Ulanowicz and Wulff, 1991). During maturation, ecosystem structure evolves towards an increase in ascendency (Ulanowicz et al., 2006). System Overhead (O) represents the amount of development capacity that does not appear as organized structure or constraints (Ulanowicz, 1986) and as such it corresponds to the system reserves when facing perturbations (Heymans and Baird, 2000).

\subsubsection{The Bay of Biscay Ecopath ensemble and ENA ensemble}

The ENAtool routine was used to generate 1000 balanced ensemble members based on the uncertainty values assigned to each input parameter according to Pedigree scores (Table 1) (Lassalle et al., 2014); for this particular food web, the search for 1000 balanced ensemble members took between three and five days to run on a single-processor machine. For each ENA index listed in Table 2, the single value obtained with the EwE software was graphically compared to the 1000 values derived from the ENAtool routine as to whether it falls between the boxplot whiskers. Then, the coefficient of variation between the mean value and the single Ecopath estimate was calculated.

The 'balance' constraint can move the parameter distribution of the balanced ensemble members away from the initial sampling distribution. It could make a crucial difference as to whether the ensemble experiment applied to the Bay of Biscay is simply adding error bars onto the input to the ENA index equations, or if it is adding error bars and shifting the mean/median value of the inputs variables. As such, an additional 1000-member ensemble based on the Bay of Biscay input dataset and Pedigree scores was generated, with keeping both balanced and unbalanced members. 
Then, the ensemble mean parameter values of these two ensembles were statistically compared using two-sample Kolmogorov-Smirnov goodness-of-fit tests (alpha $=0.05)$. generate and the level of uncertainty to be applied on $B, P / B, Q / B$, and $D C$. Therefore, it was important to study the influence of these arguments on the output variables, namely ENA indices. 1. A first exercise was performed to assess in which proportions ENA indices distributions were impacted by the number of ensemble members to generate and by the uncertainty set around input parameters in the ENAtool routine. Values for nset of 1000, 100 and 10 were tested. The point value of each parameter was changed by $20 / 40 / 60 \%$ up or down following equation (3). All combinations of nset and levels of uncertainty were run for the pre-existing Ecopath model of the Bay of Biscay continental shelf. 2. A second exercise tested which type of input parameter (i.e. $B$, $P / B, Q / B$, and $D C$ ) influenced the ENA index distributions most strongly. To do so, the ENAtool routine was run with a nset of 1000 and a level of uncertainty of $20 \%$ alternatively applied to each input parameter type of the pre-existing Ecopath model of the Bay of Biscay continental shelf (Richardson et al., 2006). In both exercises, the variance of ENA indices distributions (i.e. standard deviation squared) was the metric used to analyze the sensitivity results through graphical representations.

\section{Results}

316 First, based on the exploratory statistical comparisons of the parameter distributions between the 317 balanced ensemble and the mixed ensemble (i.e. balanced and unbalanced), 52 of the basic 318 estimates parameters shifted mean and 169 of the non-zero diet components shifted too. 
For the pre-existing Ecopath model of the Bay of Biscay continental shelf, the value derived from the EwE software for each ENA index was compared to the range of values obtained following the application of the ENAtool routine to this model with a nset of 1000 and levels of uncertainty in accordance with Pedigree scores (Table 3). For A, Ai/Ci, and MTL, the EwE single estimates fell within the range defined by the $1^{\text {st }}(25 \%)$ and the $3^{\text {rd }}(75 \%)$ quartile of ENA values (Fig. 3; Table 2 for the list of ENA indices with their abbreviations). For 9 of the 10 remaining ENA indices, the EwE single estimates fell in the upper boxplot whiskers calculated as 1.5 times the interquartile range. Regarding more specifically at the ENA indices used by Lassalle et al. (2011) in their assessment of the Bay of Biscay functioning, we calculated an FCI value with a mean of $33.09 \%$ across ensembles, compared to the single value of $34.61 \%$ obtained by Lassalle et al. (2011) (Fig. 3). The System Omnivory Index (SOI) presented the broader difference between the Ecopath single estimate and the mean value, i.e. 0.195 versus 0.179 respectively (Fig. 3); the Ecopath SOI estimate being at the upper end of the distribution. The mean Ascendency (A) was of 846015 versus 860882 flowbits for the pre-existing Ecopath model. The mean Overhead (O) and the single Overhead estimate were of 2639671 and 2947325 flowbits, respectively. The coefficients of variation between the mean values and the single Ecopath estimates for those four indices were no greater than 10\% (Table 3).

The first sensitivity exercise performed on the outputs of the ENAtool routine showed that the number of ensemble members generated induced no trend on the variance of ENA indices calculated as the standard deviation squared (Fig. 4; Table 3). Indeed, for all of the three levels of uncertainty applied in the routine, i.e. 20, 40 and $60 \%$ on all parameters, and for all ENA indices, the variance of the distribution did not systematically increase with the number of ensemble members generated as first suspected (Fig. 4). On the contrary, when looking at a given number of ensemble members to generate, i.e. at a specific shade of grey, the variance of the distribution 
systematically increased with the level of uncertainty applied to the input parameters (Table 3). This trend was particularly marked for the Total System Throughputs (TST) with variances that almost doubled when the level of uncertainty was changed from 40 to $60 \%$ (Fig. 4). These results were in line with the method, as parameters for the ensemble members were here randomly sampled from a uniform distribution with bounds directly related to the level of uncertainty; every value in the interval having the same probability of being picked.

In the second sensitivity exercise, two input parameters appeared to be the most influential on ENA indices (Fig. 5). On the one hand, the Comprehensive Cycling Index (CCI), the Finn Cycling Index (FCI), the Mean Trophic Level of captures (MTL) and the System Omnivory Index (SOI) were the most sensitive to less constrained diet compositions (DC) (Fig. 5).On the other hand, the relative Ascendency (A/C), the Ascendency (A), the Capacity (C), the Averaged Path Length (APL), the Overheads (O) and the Total System Throughput (TST) were the most sensitive to uncertainty in the Biomass (B) parameter (Fig. 5).

\section{Discussion}

The present work provides EwE modellers, and more broadly ecosystem ecologists, with a routine that generates distributions of values for a set of well-known indices synthesizing structural and functional properties of ecosystems by taking into account uncertainty in model input parameters. In the first place, reanalyzing the Bay of Biscay continental shelf food web in the light of the most probable estimates of uncertainty around input parameters for this ecosystem supported the main ENA-derived ecological conclusions. Indeed, ENA index distributions all encompassed the single ENA values derived from the EwE software with mean values in the same range as the initial Ecopath estimates (Table 3). The Bay of Biscay ensemble approach as such supported and strengthened the main conclusion of a detritus-based, and relatively mature 
ecosystem (Lassalle et al., 2011). In addition, when interpreting and using ENA distributions, it should be kept in mind that those values are derived from the propagation of parameter uncertainty forward but also, to some point, to the interplay in parameters required to keep the models balanced when any changes are made.

The ENAtool routine was developed with the primary goal of strengthening ecological conclusions derived from comparative studies and before/after impact evaluations.

Interpretation will no longer rely only on single value comparisons. The routine will permit one to test differences between ENA indices through statistical tests as performed in Saint-Béat et al. (2013) with LIM models. The LIM models have evolved in the last decade from a singlesolution method (Vézina and Platt, 1988) to statistical approaches with outputs composed of uncertainty intervals (density probability functions) of the flows and allowing the definition of uncertainty intervals of ENA indices. These methods first based on Monte Carlo approaches (Kones et al., 2006) are now used with a Monte Carlo Markov Chain routine (Kones et al., 2009). Several meta-analyses, based on a selection of EwE models, have been done, focusing either on theoretical ecology and ecological concepts, or on ecosystems and species of particular interest (see details in Colléter et al., 2013b), a growing proportion being based on ENA indices (e.g. Christensen, 1995; Pérez-España and Arreguín-Sánchez, 2001; Lobry et al., 2008; Coll and Libralato, 2012; Selleslagh et al., 2012). In the present work, complementary analyses were performed on the ENAtool routine to determine how much the ENA indices distributions were sensitive to the main routine arguments, namely the number of ensemble members to be generated (nset) and the level of uncertainty to apply on the EwE input parameters (Pedigree). The first induced no remarkable trend on the distributions whereas the latter was found positively related to the variance of the distributions (Table 3). As such, in future applications of the ENAtool routine, we recommend keeping the levels of uncertainty within a range compatible 
with known uncertainties on parameters. If no Pedigree scores were filled for the EwE model, model builders or experts of the study area should be interviewed regarding the quality of data used during model construction. This was even more strongly suggested for field biomasses $(B)$ and diet compositions $(D C)$ that appeared as the most influential input parameters (Table 3). This last result can be also interpreted as an uncertainty analysis, showing that less constrained biomasses and diet compositions in input matrices both had a marked influence on ecosystemlevel EwE model outputs such as ENA indices. This reinforces the well-known need for extra care to be used when setting these two parameters in EwE models, and more importantly for better information to be collected on these key characteristics of biological taxa. In the particular case of the Bay of Biscay, biomasses and diet compositions were both associated with low levels of uncertainty in the pre-existing Ecopath model, meaning they were already relatively well constrained by data. Within the four ENA indices that were strongly influenced by variations in diet compositions, the Mean Trophic Level (MTL) and the System Omnivory Index (SOI) were directly linked to trophic levels of functional groups compared to the Finn Cycling Index (FCI) and the Comprehensive Cycling Index (CCI) for which interpretation of diet compositions influence was less intuitive. Nonetheless, FCI and CCI were both calculated from a matrix of internal exchanges that portrays the diet compositions of predators (Allesina and Ulanowicz, 2004). Indeed, both of these indices include the term $T_{i j}$ (i.e. flow between functional groups $\mathrm{i}$ and j) in their definition, which is the same as $Q_{i j}$ in Ecopath, with $Q_{i j}=B_{j} \bullet D C_{i j}$. FCI, CCI and SOI were commonly used to assess key ecosystem structural and functional features such as system maturity (Christensen, 1995), complexity, and stability (Libralato, 2008). From an applied perspective, in a comparative study by Selleslagh et al. (2012), the SOI was also demonstrated to be positively correlated with the degree of anthropogenic perturbations in estuaries. In the context of the European Water Framework Directive, the development of more functional indicators 

based on fluxes of matters and energy, and trophic networks at the scale of the ecosystem was recently listed as a critical way to improve the implementation of European policies (Reyjol et al., 2014). In this scope, by using the ENAtool routine and by applying variations more specifically to the diet compositions, the robustness of this relationship 'SOI/anthropogenic impacts' is planned to be statistically tested in an upcoming comparative study before presentation as a potential indicator of "Good Environmental Status". Attention will have to be paid to the topology and the degree of aggregation among functional groups in the compared models as these two factors were demonstrated to influence ENA values (Johnson et al., 2009). Application of the ENAtool routine is not strictly limited to the generation of ENA indices distributions for comparative studies; it can be also used to performed conventional uncertainty analyses. There is a need to assess parameter uncertainty of EwE outputs for decision making processes. In this scope, all balanced ensemble members derived from the resampling procedure in the ENAtool routine can be stored. And then, the various graphical representations proposed in the present work and more sophisticated statistical analyses can be performed to assess the influence of less constrained parameters on model estimates. Parameter uncertainty testing is also under development by the CEFAS (UK) where alternate balanced EwE models are generated to assess the impact of parameter uncertainty on fishing policies. A new $\mathbf{R}$ package, called 'Rpath', is currently under development and will address uncertainty in input parameters allowing for a creditable interval around model outputs (Lucey et al., 2014).

5. Conclusion 

the manuscript. uncertainty testing.

\section{Acknowledgments}

ENA indices are increasingly considered as potential indicators of ecosystem status. They express, alone or in combinations, key structural and functional aspects of a given system. The ENAtool routine will help to go a step further in ecosystem-based fisheries management (EBFM) by communicating to natural resources managers the distribution and mean values of ecosystem-level indices surrounded by confidence intervals. Statistical comparison of ENA index distributions, either between neighboring ecosystems or under various management scenarios within a single ecosystem (i.e. before/after management action evaluations) can be performed using this tool, improving ecological diagnosis for a given system. Because the ENAtool routine is based on an ensemble parameterization technique, it will also contribute to the effort of the EwE community for parameter

This research has been mainly supported by the project ANTROPOSEINE (ANalysis of the

TROPhic structure and cOntribution of habitats from the SEINE River estuary) financed by the GIP-Seine Aval (http://seine-aval.crihan.fr/web/). It was also supported by the project DEVOTES (DEVelopment Of innovative Tools for understanding marine biodiversity and assessing good Environmental Status) funded by the European Union under the 7th Framework Programme, 'The Ocean for Tomorrow' Theme (grant agreement no.308392; www.devotes-project.eu). The authors wanted to thank the two anonymous reviewers for their constructive remarks on 
Figure captions

Figure 1: Schematic representation of the different Matlab functions that compose the ENAtool routine. The functions that were previously developed by Kearney (2012) are given in italics. In agreement with the developer, some modifications were made to these functions to enhance their applicability to all operating systems and to all EwE model versions. These modifications were specified in the name of the function by “_mod". The functions that were specifically built for the present work were marked in bold. The origins of formulas used in the indices functions are listed in Table 2.

Figure 2: Study area of the Bay of Biscay continental shelf and locations of the main rivers flowing into it. The shaded area corresponds to the French part of the continental shelf between 30 and 150m depth, and represents the spatial extent of the Ecopath model.

Figure 3: Boxplot of ENA indices values obtained from the ENAtool routine, run with a nset of 1000 and a level of uncertainty specific to each input parameter according to Pedigree scores for the pre-existing Ecopath model of the Bay of Biscay continental shelf of Lassalle et al. (2011). A black circle corresponds to the mean of the 1000 ENA indices values. A black cross represents

477 the single ENA indices values obtained from the pre-existing Ecopath model using the EwE 478 software. A black triangle is used for the ENA indices values calculated after the importation of 479 the pre-existing Ecopath model to Matlab with no change on the input parameters. Results are 480 depicted for the 13 ENA indices. Graphics are organized following the order of Table 2. 
482 Figure 4: Variance of ENA indices values obtained from the ENAtool routine run with every

483 combinations of $n$ set equal to 10 (light-grey bars), 100 (medium-grey bars) and 1000 (dark-grey

484 bars) and levels of uncertainty of 20, 40 and $60 \%$ on the pre-existing Ecopath model of the Bay

485 of Biscay continental shelf of Lassalle et al. (2011). Results are depicted for the 13 ENA indices.

486 Graphics are organized following the order of Table 2.

487

488 Figure 5: Variance of ENA indices values obtained from the ENAtool routine run with a nset

489 equal to 1000 and a level of uncertainty of $20 \%$ alternatively applied on each key input

490 parameter. The application case is the pre-existing Ecopath model of the Bay of Biscay

491 continental shelf of Lassalle et al. (2011). For each histogram, from the left to the right, the field

492 biomasses are modified by $\pm 20 \%$, then production to biomass ratios, consumption to biomass

493 ratios, and finally diet compositions. Results are depicted for the 13 ENA indices. Graphics are

494 organized following the order of Table 2.

495 
Table 1: Uncertainty applied to input parameters of the pre-existing Ecopath model of the Bay of Biscay continental shelf by Lassalle et al. (2011) (i.e. term 'percentage' in equation (3)). Values were derived from pre-defined tables provided by Christensen et al. (2005) associating a Pedigree score to each given level of uncertainty for each basic input parameter. Blank cells correspond to parameters left to be estimated by the model, where the parameter did not apply (e.g. $Q / B$ for primary producers), or where the EwE software did not allow setting Pedigree scores (e.g. $P / B$ of primary producers). To run the ENAtool routine, blank cells were replaced by zeros.

\begin{tabular}{|c|c|c|c|c|}
\hline & $B$ & $P / B$ & $Q / B$ & $D C$ \\
\hline Pursuit divers seabirds & 0.1 & 0.9 & 0.5 & 0.8 \\
\hline Surface feeders seabirds & 0.1 & 0.9 & 0.5 & 0.8 \\
\hline Striped dolphins & 0.1 & 0.8 & 0.5 & 0.3 \\
\hline Bottlenose dolphins & 0.1 & 0.8 & 0.5 & 0.3 \\
\hline Common dolphins & 0.1 & 0.8 & 0.5 & 0.3 \\
\hline Long-finned pilot whales & 0.1 & 0.8 & 0.5 & 0.3 \\
\hline Harbour porpoises & 0.1 & 0.8 & 0.5 & 0.3 \\
\hline Piscivorous demersal fish & 0.1 & 0.5 & 0.5 & 0.4 \\
\hline Piscivorous and benthivorous demersal fish & 0.1 & 0.5 & 0.5 & 0.4 \\
\hline Suprabenthivorous demersal fish & 0.1 & 0.5 & 0.5 & 0.4 \\
\hline Benthivorous demersal fish & 0.1 & 0.5 & 0.5 & 0.4 \\
\hline Mackerel & 0.6 & 0.5 & 0.5 & 0.3 \\
\hline Horse mackerel & 0.6 & 0.5 & 0.5 & 0.3 \\
\hline Anchovy & 0.1 & 0.5 & 0.5 & 0.3 \\
\hline Sardine & 0.1 & 0.5 & 0.5 & 0.3 \\
\hline Sprat & 0.1 & 0.5 & 0.5 & 0.3 \\
\hline Benthic cephalopods & & 0.8 & 0.8 & 0.5 \\
\hline Pelagic cephalopods & & 0.8 & 0.8 & 0.5 \\
\hline Carnivorous benthic invertebrates & 0.4 & 0.5 & & 0.3 \\
\hline Necrophageous benthic invertebrates & 0.4 & 0.5 & & 0.3 \\
\hline Sub-surface deposit feeders invertebrates & 0.4 & 0.5 & & 0.3 \\
\hline Surface suspension and deposit feeders inv. & 0.4 & 0.5 & & 0.3 \\
\hline Benthic meiofauna & 0.4 & 0.5 & & 0.3 \\
\hline Suprabenthic invertebrates & 0.4 & 0.5 & & 0.3 \\
\hline Macrozooplankton & 0.1 & & 0.8 & 0.3 \\
\hline Mesozooplankton & 0.1 & & 0.8 & 0.3 \\
\hline Microzooplankton & 0.1 & & 0.8 & 0.3 \\
\hline Bacteria & 0.1 & 0.1 & & 0.3 \\
\hline Large phytoplankton & 0.1 & & & \\
\hline Small phytoplankton & 0.1 & & & \\
\hline \multicolumn{5}{|l|}{ Discards } \\
\hline Detritus & & & & \\
\hline
\end{tabular}


Table 2: Formulas to calculate the 13 ENA indices in the indices function of the ENAtool routine. Formulas and their origins are presented for EwE software v.6 as well as for the linear inverse modelling approach. For each ENA index, its single value calculated using the EwE model of the Bay of Biscay continental shelf of Lassalle et al. (2011) was presented. $T L_{i}$ is the trophic level of the $\mathrm{i}^{\text {th }}$

functional group, $Y_{i}$ the captures (i.e. landings and discards) for functional group $i, T_{S} T_{c}$ the sum of flows involved in cycles, $T_{i j}$ the magnitude of the unidirectional flow from $i$ to $j$ (inflow), $Q_{i}$ the consumption of functional group $i, D C_{j i}$ the proportion of $j$ in the diet of $i$ and $B Q B_{i}$ (or $O I_{i}$ ) is the omnivory index for $i$. The internal ascendency $A_{i}$, internal capacity $C_{i}$ and internal relative ascendency

$A_{i} / C_{i}$ were also calculated by only considering internal flows to the system and constitute indices 11,12 and 13 respectively.

\begin{tabular}{|c|c|c|c|c|c|c|}
\hline Indices & $\begin{array}{l}\text { General } \\
\text { interpretati } \\
\text { on }\end{array}$ & EwE software formula & $\begin{array}{l}\text { Reference } \\
\mathrm{s}\end{array}$ & $\begin{array}{l}\text { Single } \\
\text { value } \\
\text { of } \\
\text { ENA } \\
\text { index }\end{array}$ & $\begin{array}{l}\text { Linear inverse modelling } \\
\text { formula }\end{array}$ & $\begin{array}{l}\text { Referenc } \\
\text { es }\end{array}$ \\
\hline $\begin{array}{l}\text { Mean } \\
\text { trophic level } \\
\text { of captures } \\
\text { (MTL) / no } \\
\text { units }\end{array}$ & $\begin{array}{l}\text { Fishing } \\
\text { down, up } \\
\text { or through } \\
\text { the food } \\
\text { web }\end{array}$ & $\frac{\sum_{i} T L_{i} \times Y_{i}}{\sum_{i} Y_{i}}$ & $\begin{array}{l}\text { Pauly et } \\
\text { al. (1998) }\end{array}$ & 3.753 & $\sim$ & \\
\hline $\begin{array}{l}\text { Total system } \\
\text { throughput } \\
(\mathrm{TST}) / \mathrm{kg} \\
\mathrm{C}_{1} \cdot \mathrm{km}^{-2} \cdot \mathrm{year}^{-}\end{array}$ & $\begin{array}{l}\text { Global } \\
\text { activity of } \\
\text { the system }\end{array}$ & $\begin{array}{l}\text { Sum of all flows, i.e. consumption, } \\
\text { respiration, imports and exports }\end{array}$ & $\begin{array}{l}\text { Ulanowic } \\
\text { z (1986) }\end{array}$ & $\begin{array}{l}93557 \\
8\end{array}$ & $\sim$ & \\
\hline $\begin{array}{l}\text { Finn cycling } \\
\text { index (FCI) } \\
\text { / no units }\end{array}$ & $\begin{array}{l}\text { Proportion } \\
\text { of flows in } \\
\text { a system } \\
\text { that is } \\
\text { recycled }\end{array}$ & $\frac{T S T_{\varepsilon}}{T S T}=\sum_{j} \frac{\sum_{i} T_{i j}+\text { Imports }_{j}}{T S T}$ & $\begin{array}{l}\text { Finn } \\
(1980)\end{array}$ & 34.61 & $\sim$ & \\
\hline
\end{tabular}




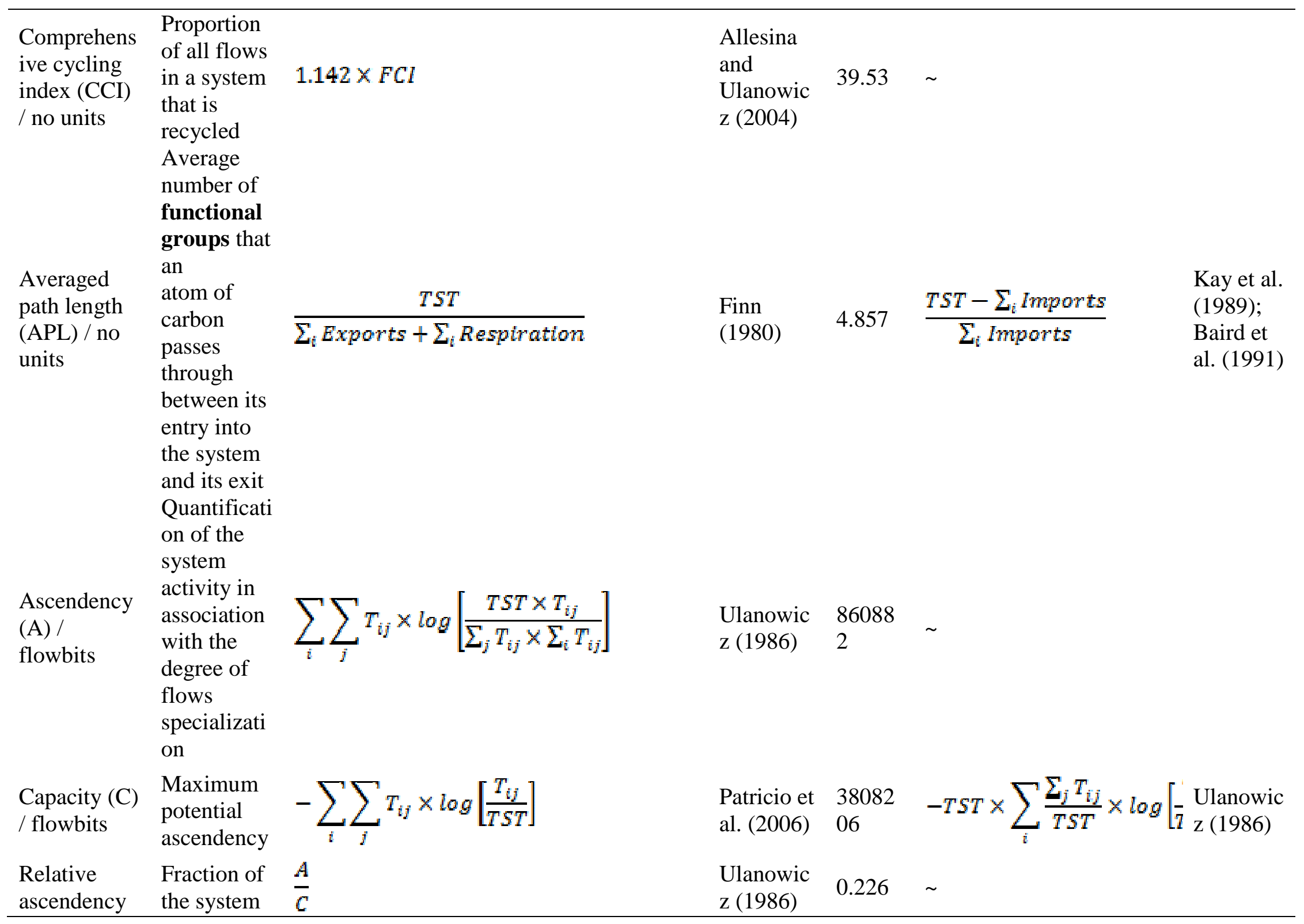




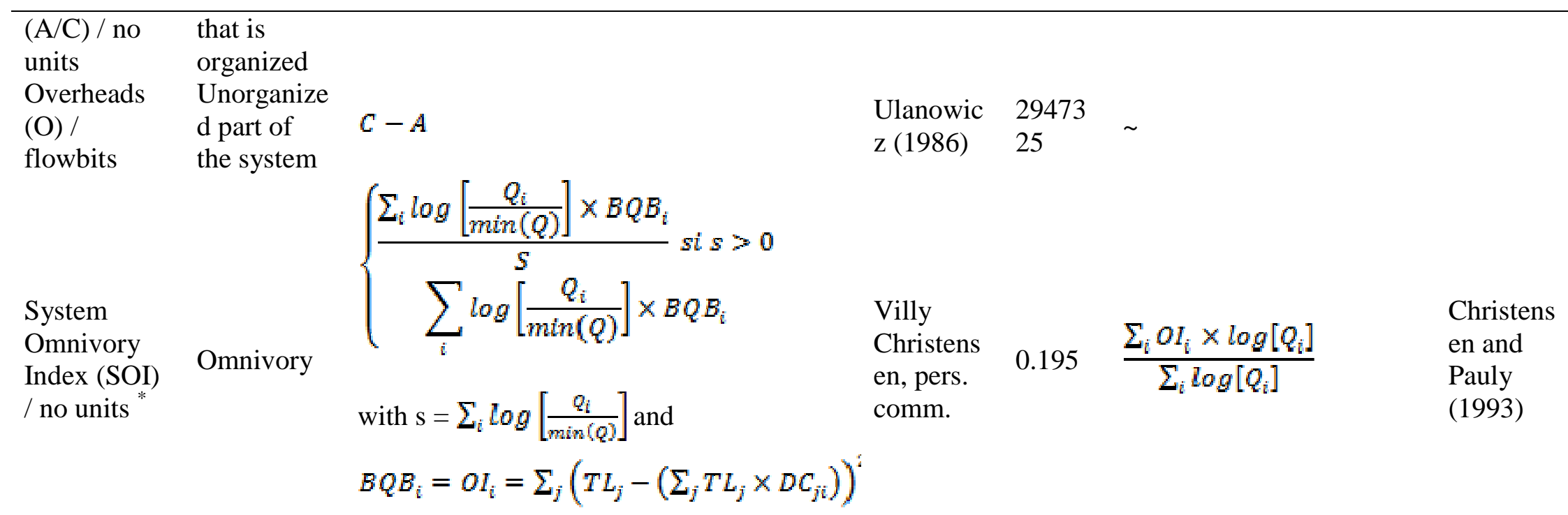


Table 3: Summary of results from the application of the ENAtool routine to the Bay of Biscay continental shelf ecosystem model and of results from the preliminary sensitivity analyses. 'Global' means that all input parameters were simultaneously changed according to the level of uncertainty and 'Local' that $B, P / B, Q / B$ and $D C$ were alternatively modified.

Application of the ENAtool routine (nset of 1000 and levels of uncertainty based on pedigrees)

- The single ENA indices values obtained from the preexisting Ecopath model using the EwE software all felt within the boxplot whisker intervals.

- The coefficients of variation between the single ENA indices values obtained from the pre-existing Ecopath model using the EwE software and the mean distribution values were comprised between 0.08 (MTL) and 11.45\% (Ci).
Preliminary sensitivity analyses

Global / All combinations of $n$ set Local / nset of 1000 and level of $(10,100,1000)$ and levels of uncertainty of $20 \%$ uncertainty $(20,40,60 \%)$

- No influence of $n s e t$ on the variance of ENA indices

- The variance of ENA indices distributions changed the distributions. most when variations were applied to $B$ and $D C$.
- The variance of ENA indices distributions systematically increased with the level of uncertainty. 

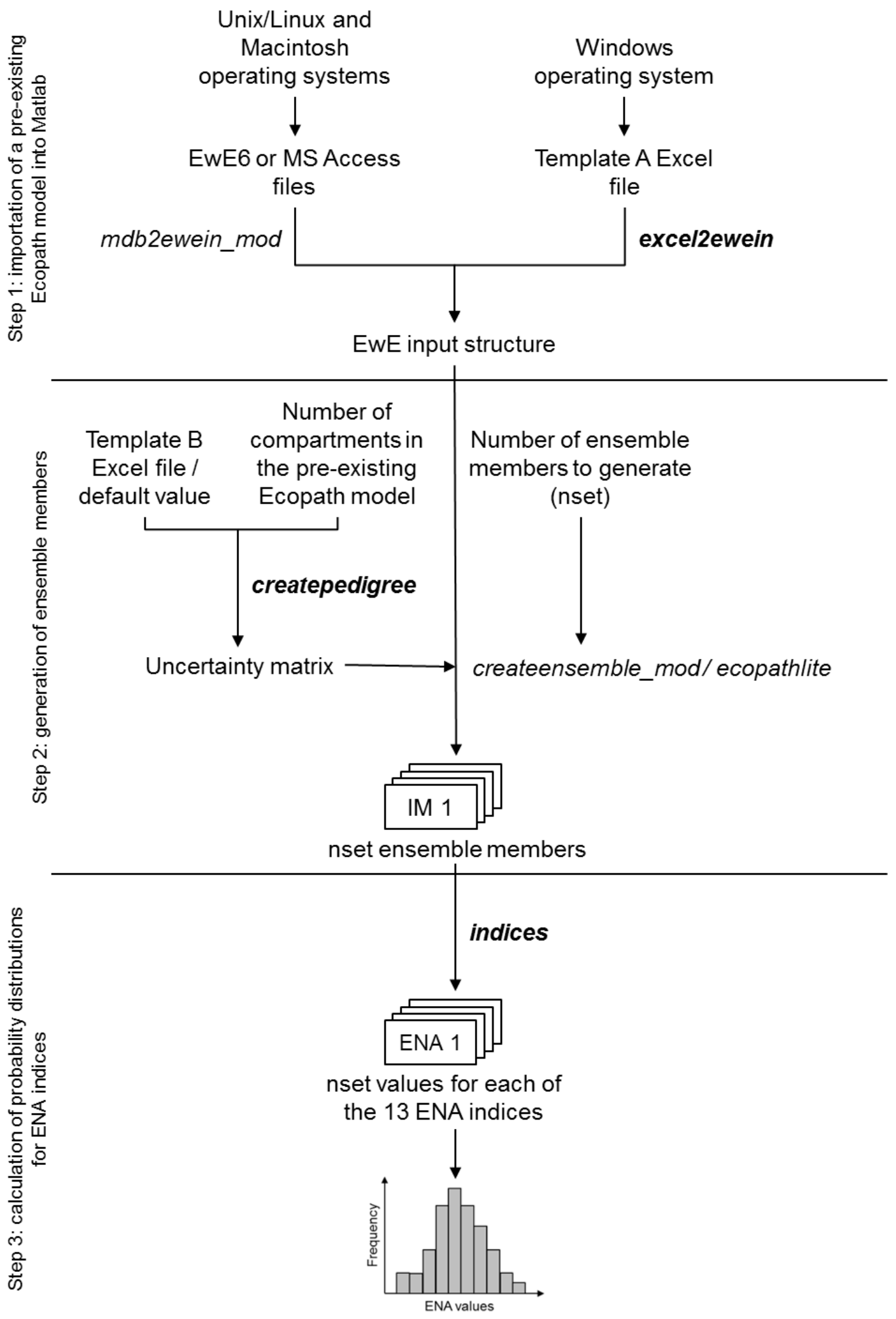


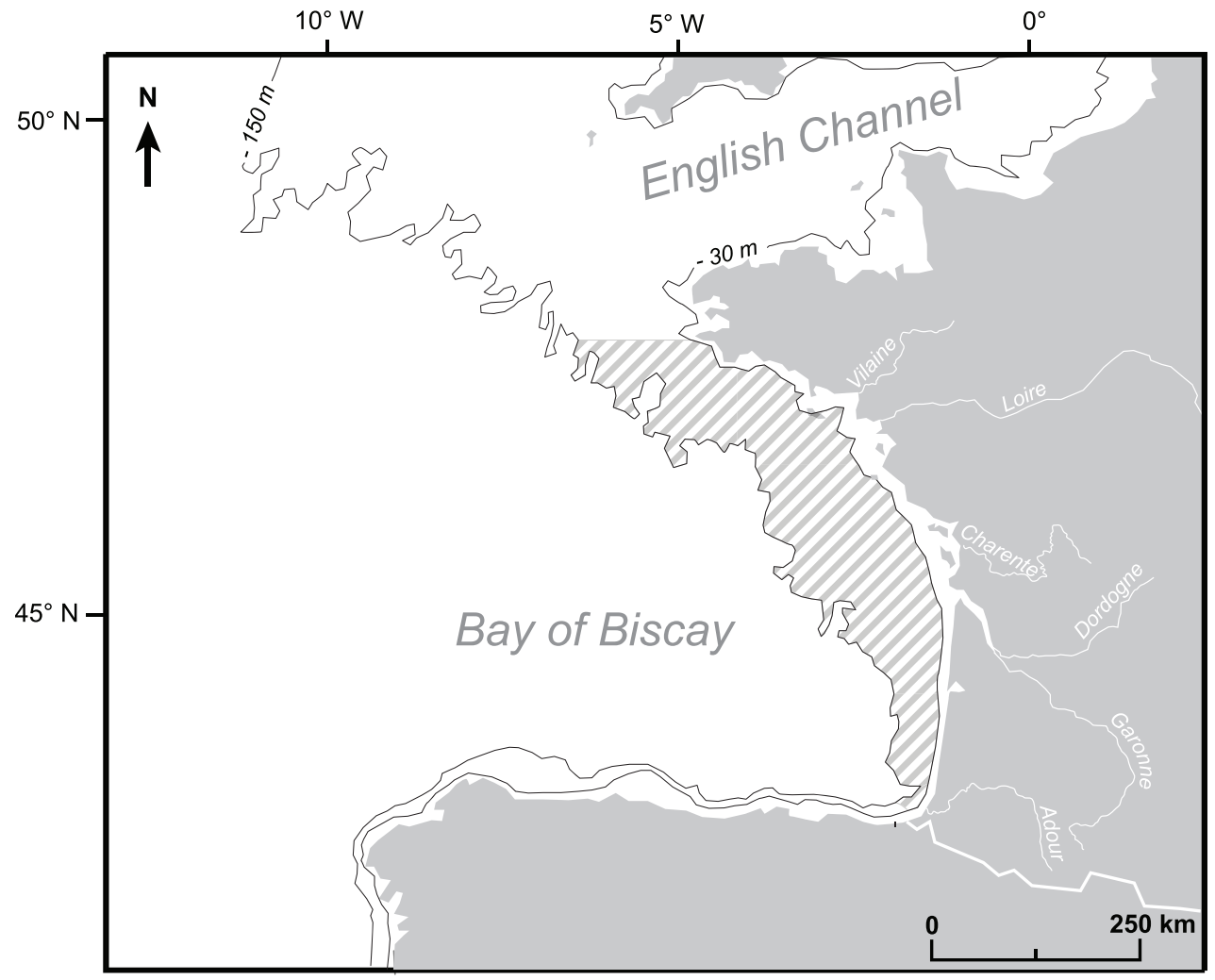


Author-produced version of the article published in Ecological modelling, 2015, 313, 23-40.
The original publication is available at http://www.sciencedirect.com/ doi : 10.1016/j.ecolmodel.2015.05.036

(c). This manuscript version is made available under the CC-BY-NC-ND 4.0 license http://creativecommons.org/licenses/by-nc-nd/4.0/

ज్
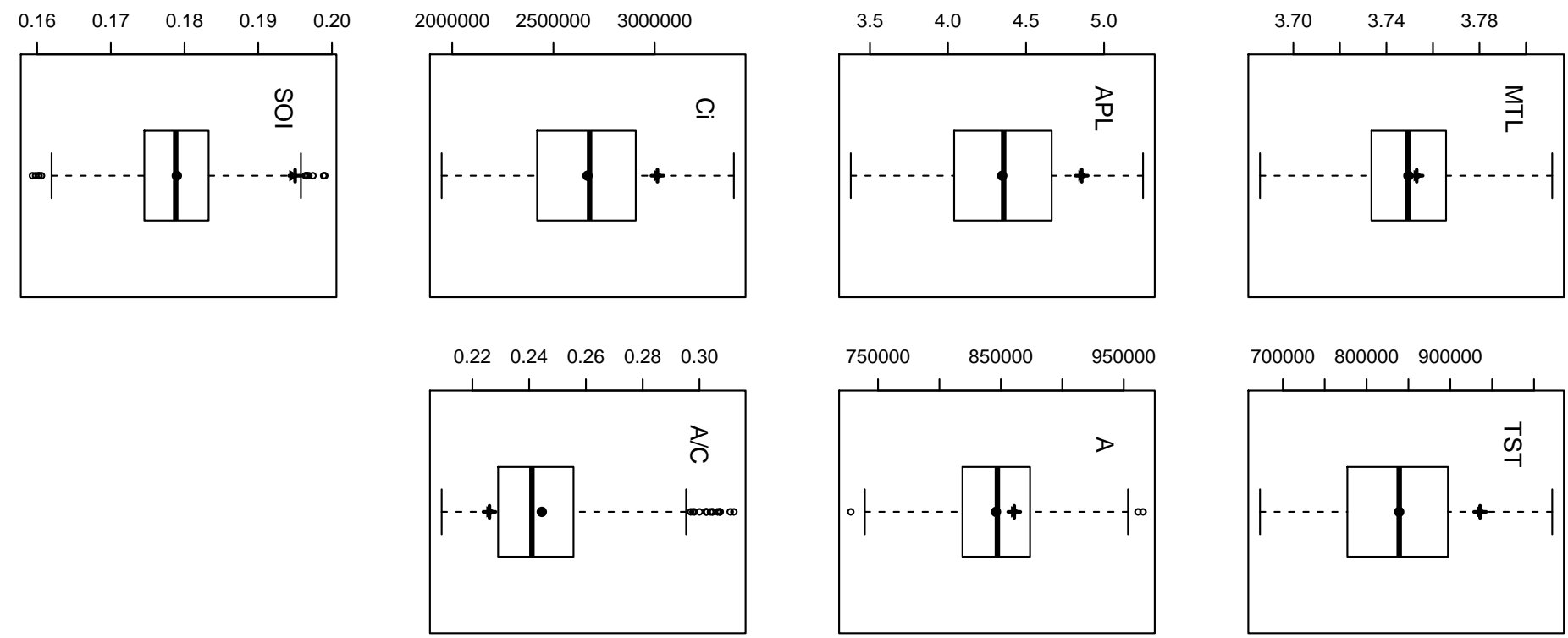

700000800000900000
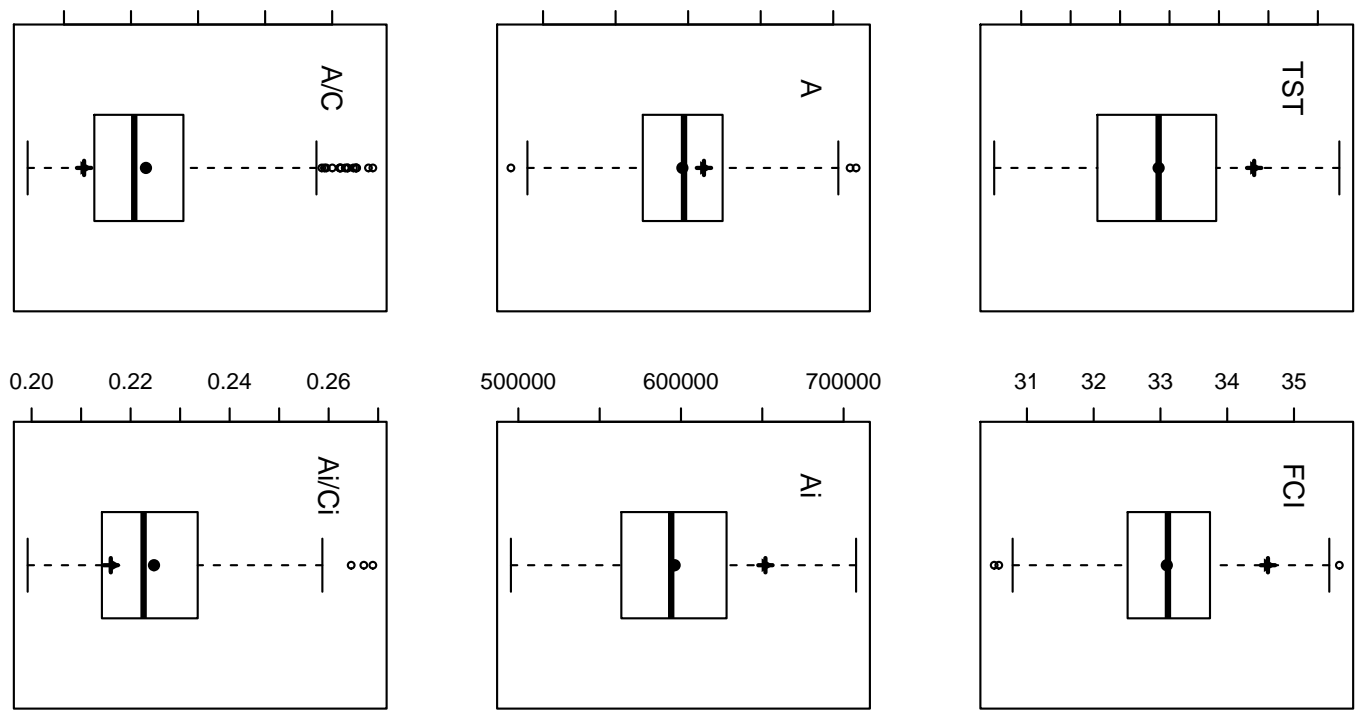

$20000002500000 \quad 3000000$
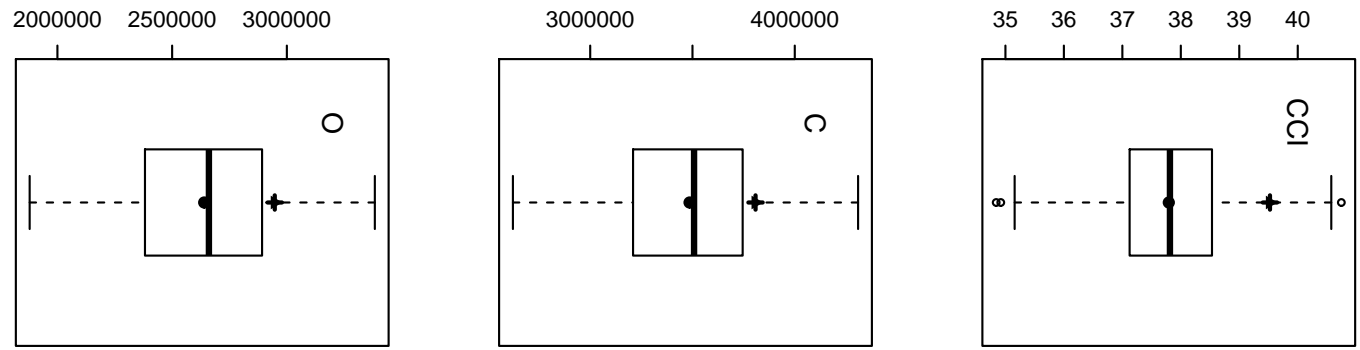
Author-produced version of the article published in Ecological modelling, 2015, 313, 23-40.
The original publication is available at http://www.sciencedirect.com/ doi : $10.1016 /$..ecolmodel.2015.05.036

๑. This manuscript version is made available under the CC-BY-NC-ND 4.0 license http://creativecommons.org/licenses/by-nc-nd/4.0/

ज
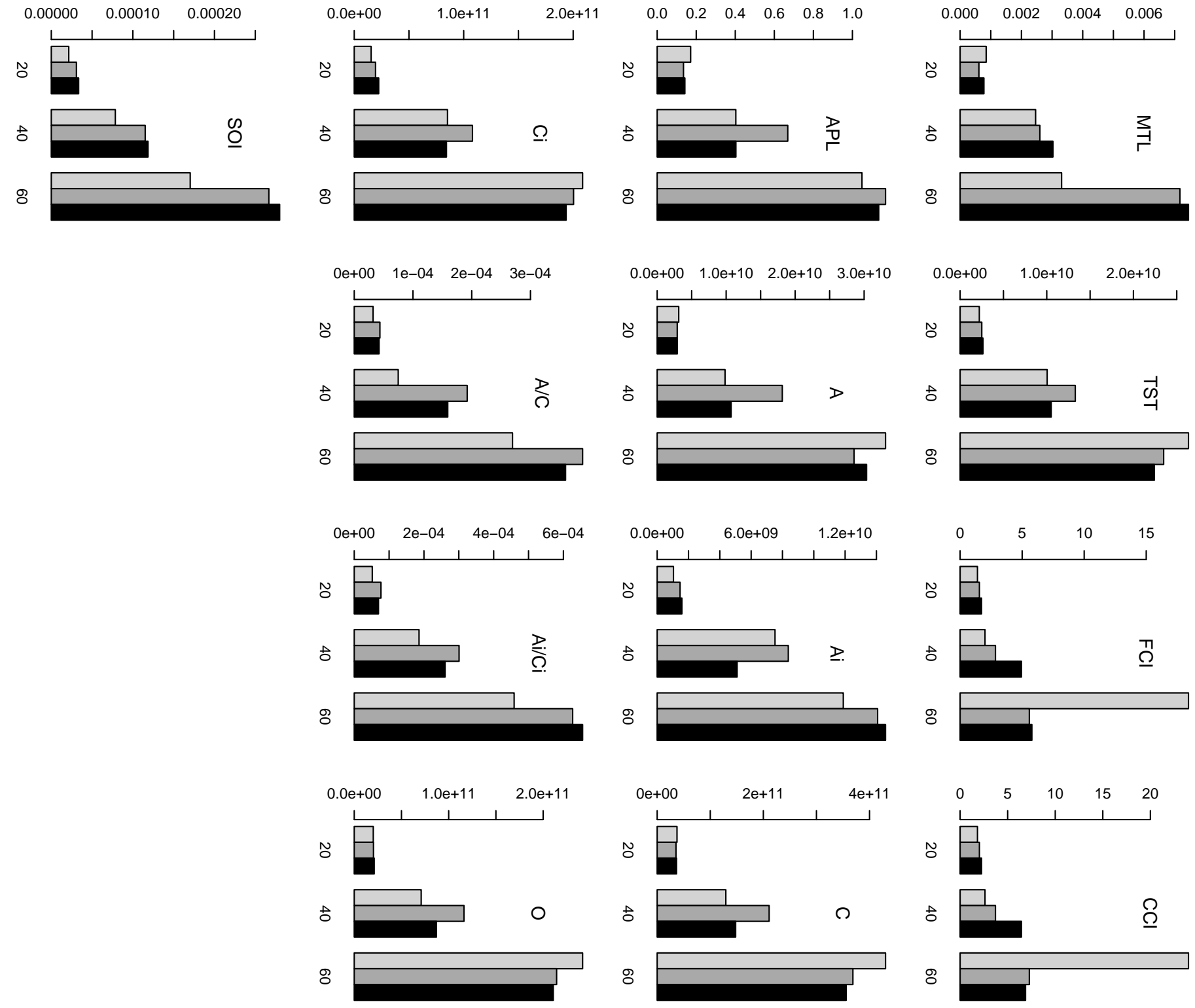

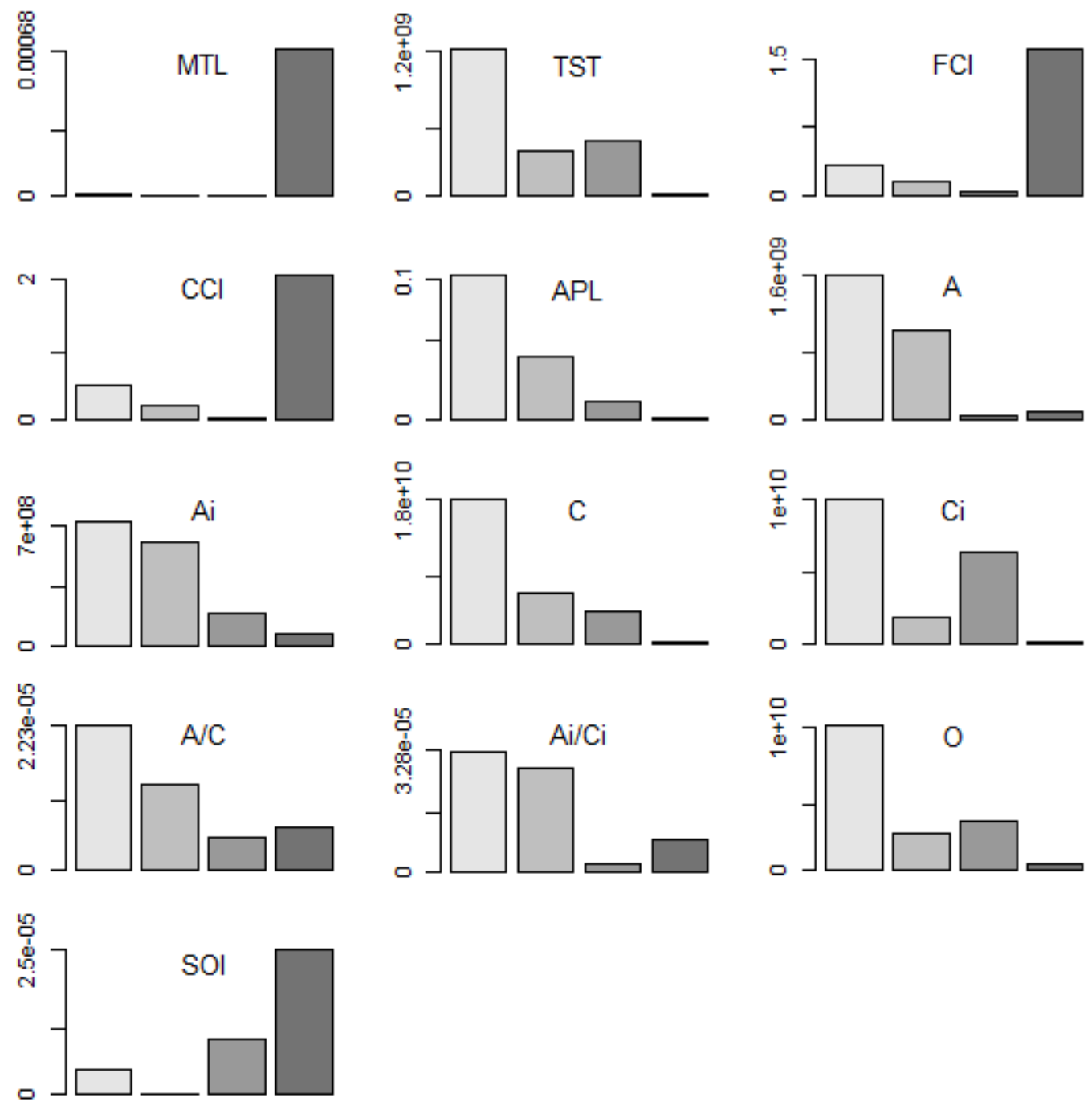
557 Allesina, S., Ulanowicz, R.E., 2004. Cycling in ecological networks: Finn's index revisited.

558 Computational Biology and Chemistry 28, 227-233.

559 Aydin, K.Y., Gaichas, S.K., Ortiz, I., Kinzey, D., Friday, N., 2007. A comparison of the Bering 560 Sea, Gulf of Alaska, and Aleutian Islands large marine ecosystems through food web modeling. 561 NOAA Technical Memorandum. 298 pp.

Baeta, A., Niquil, N., Marques, J.C., Patrício, J., 2011. Modelling the effects of eutrophication, mitigation measures and an extreme flood event on estuarine benthic food webs. Ecological Modelling 222, 1209-1221.

Baird, D., McGlade, J.M., Ulanowicz, R.E., 1991. The comparative ecology of six marine ecosystems. Philosophical Transactions of the Royal Society of London. Series B: Biological Sciences 333, 15-29.

Beaugrand, G., 2004. The North Sea regime shift: Evidence, causes, mechanisms and consequences. Progress In Oceanography 60, 245-262.

Borja, Á., Elliott, M., Carstensen, J., Heiskanen, A.-S., van de Bund, W., 2010. Marine management - Towards an integrated implementation of the European Marine Strategy Framework and the Water Framework Directives. Marine Pollution Bulletin 60, 2175-2186.

Borrett, S.R., Lau, M.K., 2014. enaR: An r package for Ecosystem Network Analysis. Methods in Ecology and Evolution 5, 1206-1213.

Christensen, V., 1995. Ecosystem maturity - towards quantification. Ecological Modelling 77, 332.

Christensen, V., Pauly, D., 1992. ECOPATH II - a software for balancing steady-state ecosystem models and calculating network characteristics. Ecological Modelling 61, 169-185. 
579 Christensen, V., Pauly, D. (ed.). 1993. Trophic models of aquatic ecosystems. International

580 Center for Living Aquatic Resources Management; The International Council for the Exploration 581 of the Sea; The Danish International Development Agency, Manila, Philippines. 390 pp.

582 Christensen, V., Walters, C.J., 2004. Ecopath with Ecosim: methods, capabilities and limitations.

583 Ecological Modelling 172, 109-139.

584 Christensen, V., Walters, C.J., Pauly, D., 2005. Ecopath with Ecosim: A user's guide. Fisheries

585 Centre, University of British Columbia, Vancouver, Canada. 154 pp.

586 Christensen, V., Walters, C.J., Pauly, D., Forrest, R., 2008. Ecopath with Ecosim version 6. User 587 guide - November 2008. Lenfest Ocean Futures Project 2008. Fisheries Centre, The University of 588 British Columbia, Vancouver, Canada. 235 pp.

589 Coll, M., Libralato, S., 2012. Contributions of foodweb modelling to the ecosystem approach to 590 marine resource management in the Mediterranean Sea. Fish and Fisheries 13, 60-88.

591 Colléter, M., Guitton, J., Gascuel, D., 2013a. An introduction to the EcoTroph R package:

592 Analyzing aquatic ecosystem trophic networks. R Journal 5, 98-107.

593 Colléter, M., Valls, A., Guitton, J., Morissette, L., Arreguín-Sánchez, F., Christensen, V.,

594 Gascuel, D., Pauly, D., 2013b. EcoBase: A repository solution to gather and communicate

595 information from EwE models. Fisheries Centre, University of British Columbia, Canada. 60 pp.

596 Dame, J.K., Christian, R.R., 2006. Uncertainty and the use of network analysis for ecosystem-

597 based fisheries management. Fisheries 31, 331-341.

598 Finn, J.T., 1980. Flow-analysis of models of the Hubbard Brook ecosystem. Ecology 61, $562-$ 599571.

600 Fulton, A.E., 2010. Approaches to end-to-end ecosystem models. Journal of Marine Systems 81, $601 \quad 171-183$. 
602 Funtowicz, S.O., Ravetz, J.R., 1990. Uncertainty and quality in science for policy. Kluwer 603 Academic Publishers. 229 pp.

604 Gårdmark, A., Lindegren, M., Neuenfeldt, S., Blenckner, T., Heikinheimo, O., Müller-Karulis, 605 B., Niiranen, S., Tomczak, M., Aro, E., Wikström, A., Möllmann, C., 2012. Biological ensemble

607 608 609 610 modelling to evaluate potential futures of living marine resources. Ecological Applications 23, $742-754$.

Heymans, J.J., Baird, D., 2000. Network analysis of the northern Benguela ecosystem by means of NETWRK and ECOPATH. Ecological Modelling 131, 97-119.

Hoegh-Guldberg, O., Bruno, J.F., 2010. The impact of climate change on the world's marine ecosystems. Science 328, 1523-1528.

Johnson, G.A., Niquil, N., Asmus, H., Bacher, C., Asmus, R., Baird, D., 2009. The effects of aggregation on the performance of the inverse method and indicators of network analysis.

Ecological Modelling 220, 3448-3464.

Kay, J.J., Graham, L.A., Ulanowizc, R.E., 1989. A detailed guide to network analysis. In: F. Wulff, J.G. Field, K.H. Mann (ed.). Network Analysis in Marine Ecology, Springer-Verlag, Berlin, Germany. pp. 15-61.

Kearney, K.A., 2012. An analysis of marine ecosystem dynamics through development of a coupled physical-biogeochemical-fisheries food web model. PhD thesis, Princeton University. $179 \mathrm{pp}$.

Kearney, K.A., 2015. A Matlab implementation of Ecopath: v0.1: Guesnet et al. 2015 snapshot. Zenodo. 10.5281/zenodo.17837.

Kearney, K.A., Stock, C., Aydin, K.Y., Sarmiento, J.L., 2012. Coupling planktonic ecosystem and fisheries food web models for a pelagic ecosystem: Description and validation for the subarctic Pacific. Ecological Modelling 237-238, 43-62. 
Kones, J.K., Soetaert, K., van Oevelen, D., Owino, J.O., 2009. Are network indices robust indicators of food web functioning? A Monte Carlo approach. Ecological Modelling 220, 370382.

Kones, J.K., Soetaert, K., van Oevelen, D., Owino, J.O., Mavuti, K., 2006. Gaining insight into food webs reconstructed by the inverse method. Journal of Marine Systems 60, 153-166. Lassalle, G., Bourdaud, P., Saint-Béat, B., Rochette, S., Niquil, N., 2014. A toolbox to evaluate data reliability for whole-ecosystem models: Application on the Bay of Biscay continental shelf food-web model. Ecological Modelling 285, 13-21.

Lassalle, G., Lobry, J., Le Loc'h, F., Bustamante, P., Certain, G., Delmas, D., Dupuy, C., Hily, C., Labry, C., Le Pape, O., Marquis, E., Petitgas, P., Pusineri, C., Ridoux, V., Spitz, J., Niquil, N., 2011. Lower trophic levels and detrital biomass control the Bay of Biscay continental shelf food web: implications for ecosystem management. Progress In Oceanography 91, 61-75.

Leguerrier, D., Degré, D., Niquil, N., 2007. Network analysis and inter-ecosystem comparison of two intertidal mudflat food webs (Brouage mudflat and Aiguillon Cove, SW France). Estuarine, Coastal and Shelf Science 74, 403-418.

Libralato, S., 2008. System Omnivory Index. In: S.E. Jorgensen, B. Fath (ed.). Encyclopedia of Ecology, Academic Press, Oxford. pp. 3472-3477.

Lobry, J., David, V., Pasquaud, S., Lepage, M., Sautour, B., Rochard, E., 2008. Diversity and stability of an estuarine trophic network. Marine Ecology Progress Series 358, 13-25.

Lucey, S.M., Aydin, K.Y., Gaichas, S.K., Fogarty, M.J., Hyun, S.-Y., Cadrin, S.X., 2014. Improving the EBFM toolbox with an open source mass balance model. In: J. Steenbeek, C. Piroddi, M. Coll, J.J. Heymans, S. Villasante, V. Christensen (ed.) Ecopath 30 years conference proceedings: Extended abstracts, Fisheries Centre, University of British Columbia, Canada. pp. 204-205. 
650 Niiranen, S., Blenckner, T., Hjerne, O., Tomczak, M., 2012. Uncertainties in a Baltic Sea food-

651 web model reveal challenges for future projections. Ambio 41, 613-625.

652 Niquil, N., Kagami, M., Urabe, J., Christaki, U., Viscogliosi, E., Sime-Ngando, T., 2011.

653 Potential role of fungi in plankton food web functioning and stability: a simulation analysis based 654 on Lake Biwa inverse model. Hydrobiologia 659, 65-79.

655 Niquil, N., Le Loc'h, F., Tecchio, S., Chaalali, A., Vouriot, P., Mialet, B., Fizzala, X., Féral, J.-

656 P., Lamare, S., Dauvin, J.-C., Safi, G., 2014. Ongoing research on ecosystem health indicators for 657 food webs in the MSFD context. In: E. Evariste, J.-C. Dauvin, P. Claquin, A. Auber, A. Winder, 658 B. Thenail, S. Fletcher, J.-P. Robin (ed.) Trans-Channel forum proceedings "Science and 659 Governance of the Channel Marine Ecosystem", INTERREG IV A Programme, Université de 660 Caen Basse-Normandie, Caen, France. pp. 160.

661 Odum, E.P., 1969. The strategy of ecosystem development. Science 164, 262-270.

662 Patricio, J., Ulanowicz, R., Pardal, M.A., Marques, J.C., 2006. Ascendency as ecological 663 indicator for environmental quality assessment at the ecosystem level: A case study. In: K.

664 Martens, H. Queiroga, M.R. Cunha, A. Cunha, M.H. Moreira, V. Quintino, A.M. Rodrigues, J.

665 Seroôdio, R.M. Warwick (ed.). Marine Biodiversity, Springer Netherlands. pp. 19-30.

666 Pauly, D., Christensen, V., Walters, C., 2000. Ecopath, Ecosim, and Ecospace as tools for

667 evaluating ecosystem impact of fisheries. ICES Journal of Marine Science 57, 697-706.

668 Pauly, D., Christensen, V., Dalsgaard, J., Froese, R., Torres, F., 1998. Fishing down marine food 669 webs. Science 279, 860-863.

670 Pérez-España, H., Arreguín-Sánchez, F., 2001. An inverse relationship between stability and 671 maturity in models of aquatic ecosystems. Ecological Modelling 145, 189-196.

672 Plagànyi, E.E., 2007. Models for an ecosystem approach to fisheries. FAO, Rome, Italy. 107 pp. 
673 Polovina, J.J., 1984. Model of coral reef ecosystem I. The Ecopath model and its application to

674 French Frigate Shoals. Coral Reefs 3, 1-11.

675 Reyjol, Y., Argillier, C., Bonne, W., Borja, A., Buijse, A.D., Cardoso, A.C., Daufresne, M.,

676 Kernan, M., Ferreira, M.T., Poikane, S., Prat, N., Solheim, A.-L., Stroffek, S., Usseglio-Polatera,

677 P., Villeneuve, B., van de Bund, W., 2014. Assessing the ecological status in the context of the

678 European Water Framework Directive: Where do we go now? Science of The Total Environment $679 \quad 497-498,332-344$.

680 Richardson, T.L., Jackson, G.A., Ducklow, H.W., Roman, M.R., 2006. Spatial and seasonal 681 patterns of carbon cycling through planktonic food webs of the Arabian Sea determined by 682 inverse analysis. Deep Sea Research Part II: Topical Studies in Oceanography 53, 555-575.

683 Rombouts, I., Beaugrand, G., Fizzala, X., Gaill, F., Greenstreet, S., Lamare, S., Le Loc'h, F., 684 McQuatters-Gollop, A., Mialet, B., Niquil, N., Percelay, J., Renaud, F., Rossberg, A., Féral, J.-P., 685 2013. Food web indicators under the Marine Strategy Framework Directive: From complexity to 686 simplicity? Ecological Indicators 29, 246-254.

687 Saint-Béat, B., Baird, D., Asmus, H., Asmus, R., Bacher, C., Pacella, S.R., Johnson, G.A., David, 688 V., Vézina, A.F., Niquil, N., 2015. Trophic networks: How do theories link ecosystem structure 689 and functioning to stability properties? A review. Ecological Indicators 52, 458-471.

690

691
Saint-Béat, B., Dupuy, C., Bocher, P., Chalumeau, J., De Crignis, M., Fontaine, C., Guizien, K., Lavaud, J., Lefebvre, S., Montanié, H., Mouget, J.-L., Orvain, F., Pascal, P.-Y., Quaintenne, G., Radenac, G., Richard, P., Robin, F., Vézina, A.F., Niquil, N., 2013. Key features of intertidal food webs that support migratory shorebirds. PLoS ONE 8, e76739.

Selleslagh, J., Lobry, J., Amara, R., Brylinski, J.M., Boët, P., 2012. Trophic functioning of coastal ecosystems along an anthropogenic pressure gradient: A French case study with emphasis on a small and low impacted estuary. Estuarine, Coastal and Shelf Science 112, 73-85. 
697 Tomczak, M.T., Heymans, J.J., Yletyinen, J., Niiranen, S., Otto, S.A., Blenckner, T., 2013.

698 Ecological network indicators of ecosystem status and change in the Baltic sea. PLoS ONE 8, $699 \mathrm{e} 75439$.

700 Ulanowicz, R.E., 1986. Growth and development: Ecosystem phenomenology. Springer-Verlag,

701 New-York, USA. 203 pp.

702 Ulanowicz, R.E., 2004. Quantitative methods for ecological network analysis. Computational

703 Biology and Chemistry 28, 321-339.

704 Ulanowicz, R.E., Wulff, F., 1991. Comparing ecosystem structures: The Chesapeake Bay and the

705 Baltic Sea. In: J. Cole, G. Lovett, S. Findlay (ed.). Comparative Analysis of Ecosystems -

706 Patterns, Mechanisms and Theories, Springer-Verlag, New-York, USA. pp. 140-166.

707 Ulanowicz, R.E., Jørgensen, S.E., Fath, B.D., 2006. Exergy, information and aggradation: An

708 ecosystems reconciliation. Ecological Modelling 198, 520-524.

709 Vézina, A.F., Platt, T., 1988. Food web dynamics in the oceans. 1. Best-estimates of flow

710 networks using inverse methods. Marine Ecology Progress Series 42, 269-287. 